\title{
REKONSTRUKSI PALEOBATIMETRI DAN PENENTUAN BATAS PENGENDAPAN BERDASARKAN KELIMPAHAN FORAMINIFERA: STUDI KASUS PADA SEDIMEN INTI SO189/2-04KL DI CEKUNGAN BENGKULU
}

\section{PALEOBATHYMETRY RECONSTRUCTION AND DEPOSITIONAL BOUNDARY BASED ON FORAMINIFERA ABUNDANCE: A CASE STUDY ON SO189/2-04KL SEDIMENT CORE IN BENGKULU BASIN}

\author{
Taufan Wiguna $^{1,2}$, Sri Ardhyastuti ${ }^{3}$ \\ ${ }^{1}$ Program Studi Magister Teknik Geologi, Institut Teknologi Bandung, Jl. Ganesha 10, Bandung \\ ${ }^{2}$ Balai Teknologi Survei Kelautan, Badan Pengkajian dan Penerapan Teknologi (BPPT), \\ Jl. MH. Thamrin No. 8, Jakarta \\ ${ }^{3}$ Pusat Teknologi Reduksi Risiko Bencana, Badan Pengkajian dan Penerapan Teknologi \\ (BPPT), Kawasan Puspiptek, Serpong, Tangerang Selatan \\ E-mail:taufan.wiguna@bppt.go.id
}

\begin{abstract}
ABSTRAK
Rekonstruksi paleobatimetri dan penentuan batas pengendapan dalam eksplorasi migas telah digunakan untuk mengetahui sejarah geologi suatu cekungan. Pendekatan ini dapat dilakukan dengan menggunakan proksi mikrofosil, salah satunya foraminifera. Penelitian ini menggunakan data kelimpahan foraminifera untuk merekonstruksi paleobatimetri dan menentukan batas pengendapan pada sedimen inti SO189/2-04KL 600-900 cmbsf di Cekungan Bengkulu. Metodologi yang digunakan adalah dengan rasio P/B dan kelimpahan foraminifera planktonik. Sebagai hasil, perubahan parameter foraminifera menunjukkan adanya perubahan paleobatimetri antara neritik luar dan batial bawah. Batial bawah hanya muncul pada interval 780-785 cmbsf. Bidang banjir maksimum (MFS) berada di kedalaman 640, 736,5, dan 825 cmbsf, sedangkan bidang transgresif (TS) berada di kedalaman 701, 765, dan $890 \mathrm{cmbsf}$.
\end{abstract}

Kata Kunci: paleobatimetri, bidang banjir maksimum, bidang transgresif, rasio P/B, kelimpahan foraminifera

\begin{abstract}
[Paleobathymetry Reconstruction and Depositional Boundary Based on Foraminifera Abundance: a Case Study on So189/2-04kl Sediment Core in Bengkulu Basin] Paleobathymetry reconstruction and deposition boundary determination in an oil and gas industry has been used widely to study geological history on a basin. Those approaches could be done by microfossil proxy, including use of foraminifera. Using the foraminifera abundance and P/B ratio, this study tries to reconstruct paleobathymetry and determine depositional boundary on sediment core SO189/2-04KL 600-900 cmbsf in Bengkulu Basin. As a result, both parameters show paleobathymetry changes between outer neritic and inner bathyal. Inner bathyal only appear on interval 780-785 cmbsf. Maximum flooding surface appear on depth 640, 736.5, and $825 \mathrm{cmbsf}$ while transgressive surface appears on depth 701, 765, and $890 \mathrm{cmbsf}$.
\end{abstract}

Keywords: paleobathymetry, maximum flooding surface transgressive surface, $P / B$ ratio, foraminifera abundance 


\section{PENDAHULUAN}

Rekonstruksi paleobatimetri secara umum telah digunakan dalam eksplorasi migas untuk determinasi sejarah pengendapan cekungan migas (Vail dan Wornardt 1991; Mitchum dkk., 1993) dan lingkungan purba (Lagoe, 1987). Variasi paleobatimetri berkorelasi dengan perubahan tinggi permukaan laut dan iklim (Lagoe, 1987). Barron dan Keller (1983) dalam Lagoe (1987) menunjukkan pola coastal onlap, yang terbentuk akibat permukaan laut naik dan iklim relatif hangat. Ketinggian permukaan laut maksimum berasosiasi dengan bidang banjir maksimum (MFS: Maximum Flooding Surface), yaitu ketika permukaan laut berada di level tertinggi (Catuneanu dkk., 2012). Endapan sedimen pada MFS berupa sedimen pelagik - hemipelagik yang berbutir halus (lempung-lanau) dan kaya material organik yang berpotensi sebagai sumberdaya migas. Oleh sebab itu mempelajari paleobatimetri dan MFS sangat penting untuk mengetahui sejarah dan potensi geologi suatu cekungan.

Paleobatimetri dapat ditentukan dengan menggunakan rasio jumlah foraminifera planktonik dan bentonik. Kumpulan foraminifera dapat dipengaruhi oleh faktor kedalaman, salinitas, nutrisi, cahaya matahari, arus dan gelombang sehingga dapat digunakan sebagai indikator perubahan lingkungan (Boltovskoy dan Wright, 1976; Gupta, 1999; Murray, 2006). Cekungan Bengkulu merupakan salah satu cekungan busur muka di barat Sumatra yang terbentuk sejak awal Tersier. Wiedicke-Hombach dkk. (2006) menunjukkan adanya potensi migas di cekungan namun belum ditemukan dalam jumlah komersial. Lückge (2009a) menyebutkan bahwa iklim di area ini dapat dipengaruhi oleh insolasi dan oseanografi dari satu lokasi sedimen inti, sehingga diperlukan perbandingan dengan lokasi lainnya. Berdasarkan hal tersebut, diperlukan data baru di Cekungan Bengkulu yang dapat menjadi informasi tambahan bagi eksplorasi migas sekaligus mengkonfirmasi kondisi paleoklimat di area tersebut, salah satunya adalah rekonstruksi paleobatimetri dan penentuan batas pengendapan. Penelitian ini bertujuan untuk merekonstruksi paleobatimetri dan menentukan MFS di Cekungan Bengkulu, perairan Sumatra bagian selatan melalui kelimpahan foraminifera.

\section{METODOLOGI}

\subsection{Sampel dan Sampling}

Sampel yang digunakan untuk merekonstruksi paleobatimetri dan menentukan MFS adalah sedimen inti (core sediment) SO189/2-04KL kedalaman 600-900 cm di bawah dasar laut (cmbsf: cm below sea floor). Sampel sedimen inti ini diambil di perairan barat Sumatra, yaitu Cekungan Bengkulu pada kedalaman air 1705 m (Gambar 1). Preparasi sampel foraminifera diambil dari cuplikan contoh sedimen secara sistematis dengan interval 1-2 $\mathrm{cm}$ dan spasi $1 \mathrm{~cm}$ dan $5 \mathrm{~cm}$ (Gambar 1). Sampel ini diperoleh dari Laboratorium Conto Inti pada Pusat Penelitian Geologi Kelautan di Cirebon. Sampel sedimen inti diambil dari lokasi studi pada periode waktu 4 September - 5 Oktober 2006 menggunakan R.V. Sonne melalui program SUMATRA - The hydrocarbon system of the Sumatra forearc (Wiedicke-Hombach dkk., 2006) dan kemudian disimpan di laboratorium tersebut. Sedangkan untuk preparasi sampel foraminifera, sampel diambil dari cuplikan conto sedimen secara sistematis dengan interval 1-2 cm dan spasi $1 \mathrm{~cm}$ dan $5 \mathrm{~cm}$ (Gambar 1), kemudian ditimbang sekitar $10 \mathrm{gr}$ per conto sedimen. Untuk mendapatkan foraminifera di dalam sedimen, sedimen dicuci 
dan disaring dengan ukuran mesh 80 dan 100, lalu dikeringkan dengan oven bersuhu 60 ${ }^{\circ} \mathrm{C}$.

\subsection{Analisis Paleobatimetri}

Metode yang digunakan untuk penentuan paleobatimetri adalah analisis rasio P/B, sedangkan bidang MFS ditentukan dengan kelimpahan maksimum foraminifera planktonik (Maryunani, 1998). Untuk kebutuhan analisis rasio P/B, ditentukan klasifikasi foraminifera planktonik dan bentonik berdasarkan morfologi cangkangnya (Boltovskoy dan Wright, 1976). Identifikasi dilakukan sebanyak 300 individu per sampel yang merepresentasikan 95\% seluruh kemunculan fosil dalam sampel (Dennison dan Hay, 1967). Setelah itu data kelimpahan individu foraminifera di normalisasi dengan persamaan berikut (Ardi dkk., 2019):

$$
\begin{aligned}
(\mathrm{N}) & =2^{\mathrm{n}} \times A \\
(\mathrm{Nz}) & =\left(\mathrm{m}_{\mathrm{a}} / \mathrm{m}_{\mathrm{b}}\right) \times \mathrm{N}
\end{aligned}
$$

dengan:

$$
\begin{array}{ll}
\mathrm{N} & =\text { Jumlah individu di dalam sampel } \\
\mathrm{n} & =\text { jumlah split } \\
\mathrm{A} & =\text { jumlah spesies pada satu bagian } \\
\mathrm{Nz} & =\text { jumlah individu di dalam sampel ternormalisasi } \\
\mathrm{m}_{\mathrm{a}} & =\text { massa ditimbang } \\
\mathrm{m}_{\mathrm{b}} & =\text { massa diharapkan }
\end{array}
$$

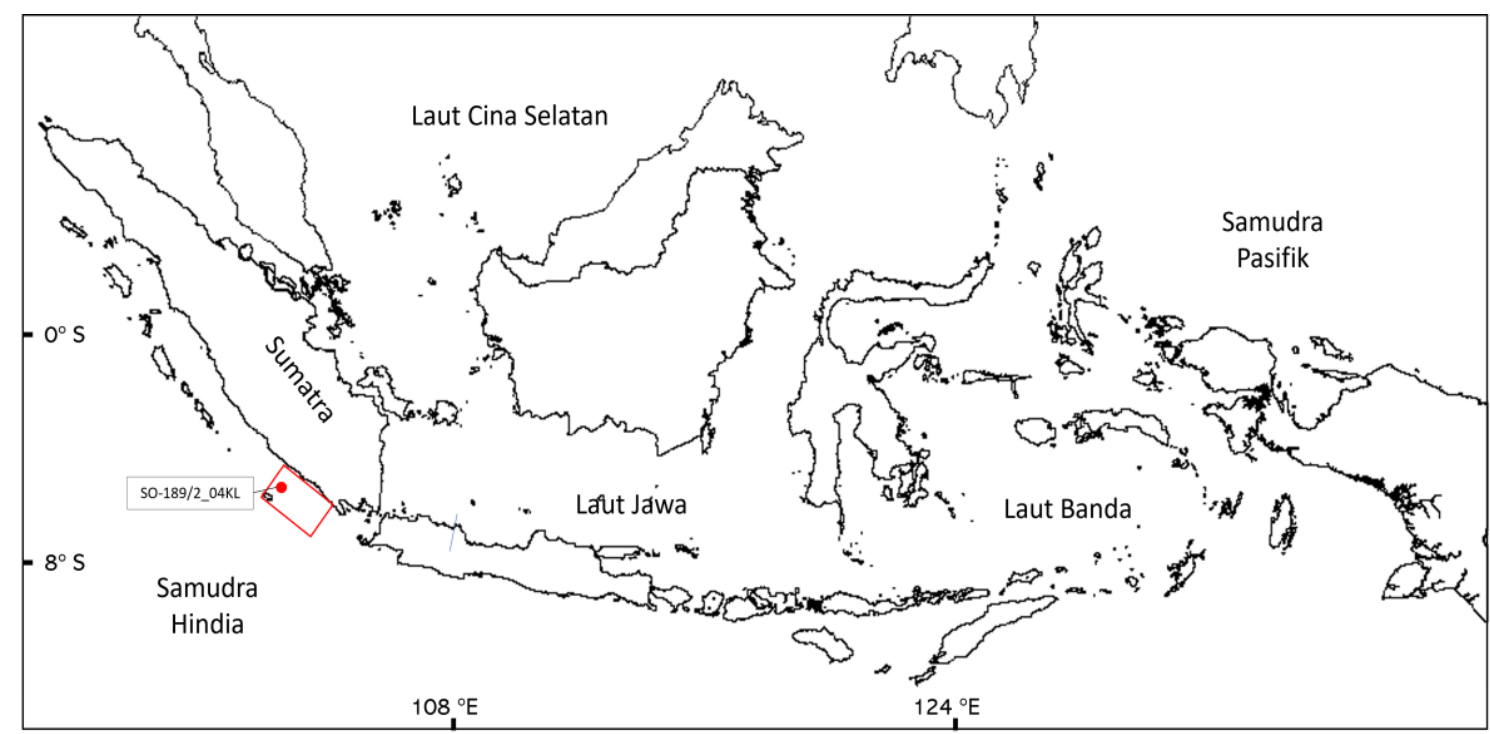

Gambar 1. Lokasi SO189/2-04KL di Cekungan Bengkulu berada di busur muka Barat Sumatra.

Rasio P/B adalah persentase kelimpahan foraminifera planktonik terhadap seluruh kelimpahan foraminifera (jumlah planktonik dan bentonik). Secara matematis, rasio P/B adalah sebagai berikut (van Marle, 1989):

$$
\text { Rasio P/B = P / (P+B) x 100\% }
$$

dengan:

$\mathrm{P}=$ jumlah individu plantonik

$\mathrm{B}=$ jumlah individu bentonik 
Klasifikasi paleobatimetri berdasarkan rasio $\mathrm{P} / \mathrm{B}$ yang digunakan adalah klasifikasi Grimsdale dan Van Morkhovern (1955) yang ditunjukkan pada Tabel 1.

Tabel 1. Klasifikasi lingkungan berdasarkan rasio P/B

\begin{tabular}{ccc}
\hline No & P/B \% & Lingkungan Batimetri \\
\hline 1 & $<20$ & Neritik Dalam \\
2 & $20-60$ & Neritik Tengah \\
3 & $40-70$ & Neritik Luar \\
4 & $>70$ & Batial Atas \\
5 & $>95$ & Batial bawah \\
\hline
\end{tabular}

\section{HASIL DAN PEMBAHASAN}

Kelimpahan foraminifera planktonik bervariasi dari 128 hingga 984 individu dan bentik antara 0 hingga 172 individu, sedangkan rasio P/B antara 57,5 dan $100 \%$. Berdasarkan klasifikasi Grimsdale dan Van Morkhovern (1955), kedalaman area penelitian antara neritic atas dan batial atas. Batial atas hanya muncul pada kedalaman 780-785 cmbsf. Kelimpahan tertinggi planktonik foraminifera diinterpretasikan sebagai MSF muncul pada kedalaman 640, 736,5, dan $825 \mathrm{cmbsf}$ dan kelimpahan terendah diinterpretasikan sebagai TS muncul pada kedalaman 701, 765, dan 890 cmbsf (Gambar 2).

Perubahan rasio $\mathrm{P} / \mathrm{B}$ disetiap interval dapat merepresentasikan perubahan paleobatimetri. Perubahan ini mungkin dapat disebabkan oleh perubahan iklim global dan tektonik dan kecepatan sedimentasi yang sifatnya lokal. Jika kecepatan sedimentasi di SO189/2-04KL diasumsikan sama dengan SO139-74KL (Lückge dkk., 2009b; 7,2 $\mathrm{cm}$ per 1000 tahun), yang berada sekitar $290 \mathrm{~km}$ di sebelah selatan lokasi penelitian, maka interval sedimen penelitian berada pada umur Pleistosen Akhir dan MFS-1 dan MFS-2 memiliki selisih umur 12.291 tahun, sedangkan MFS-2 dan MFS-3 memiliki selisih umur 13.402 tahun. Selisih waktu tersebut termasuk dalam order ke 6 dalan sikuen stratigrafi (Schlager, 2009).

Meskipun secara kuantitatif puncak-puncak rasio $\mathrm{P} / \mathrm{B}$ dan kelimpahan foraminifera planktonik sama, namun secara kuantitatif, nilai korelasinya rendah (Tabel 2). Hal ini dapat disebabkan oleh faktor lain yang mempengaruhi keragaman dan distribusi foraminifera, selain kedalaman, seperti salinitas, arus dan gelombang (Boltovskoy dan Wright, 1976).

Tabel 2. Hasil uji korelasi kelimpahan relatif foraminifera planktonik dan rasio P/B

$$
\text { Variables Planktonik Rasio P/B }
$$

\begin{tabular}{clrr}
\hline \multirow{2}{*}{ Matriks Korelasi } & Planktonik & $\mathbf{1}$ & 0.368 \\
& Rasio P/B & 0.368 & $\mathbf{1}$ \\
\hline \multirow{2}{*}{ Koefisien Determinasi } & Planktonik & $\mathbf{1}$ & 0.135 \\
& Rasio P/B & 0.135 & $\mathbf{1}$ \\
\hline
\end{tabular}



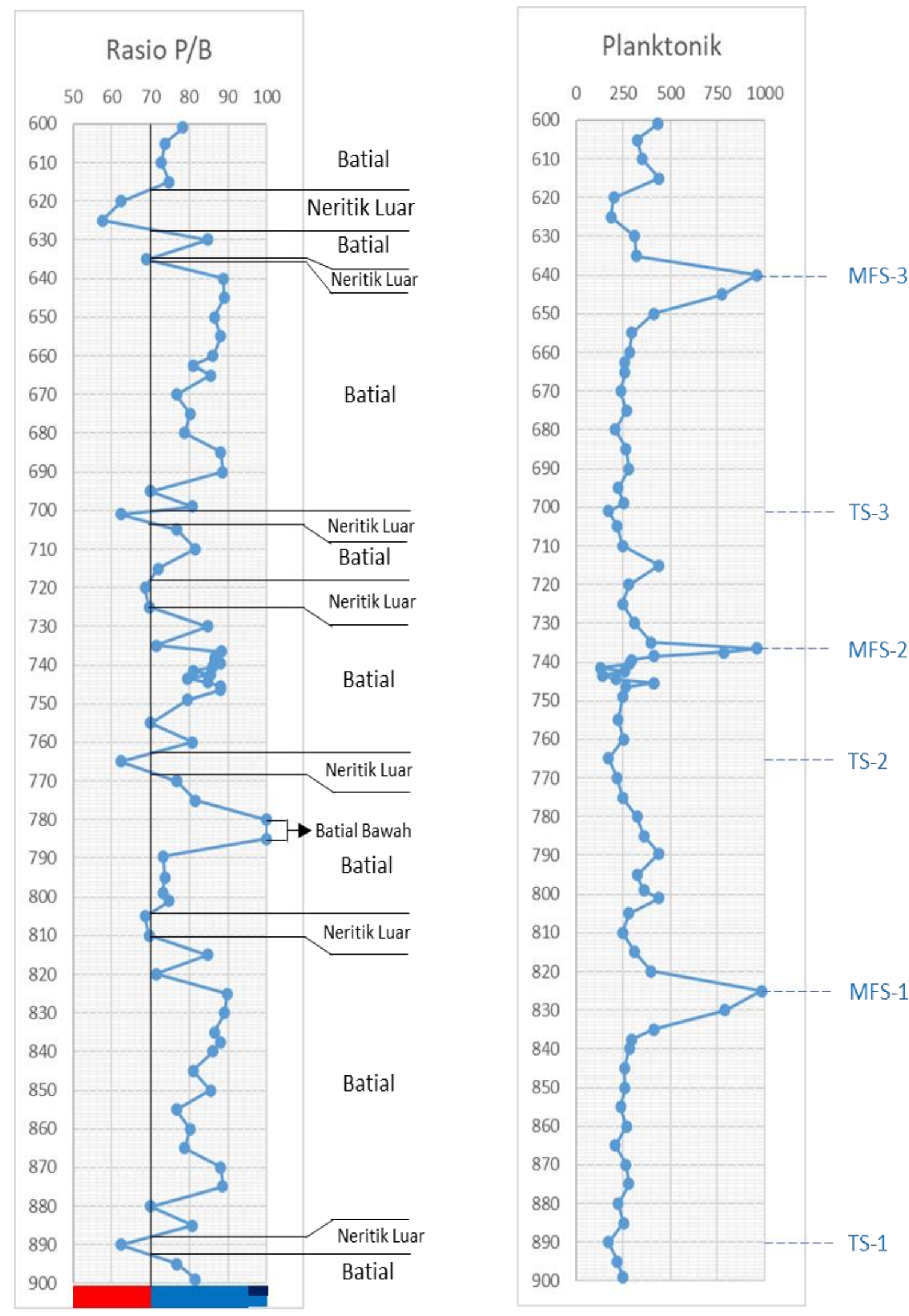

Neritik Luar $\square$ Batial Atas

Batial Bawah

Gambar 2. Rasio P/B dan kelimpahan foraminifera planktonik pada SO189/2-04KL 


\section{KESIMPULAN}

Sedimen inti SO189/2-04KL: 600-800 cmbsf menunjukkan adanya perubahan paleobatimetri antara neritik luar dan batial bawah. Batial bawah hanya muncul pada interval 780-785 cmbsf. Bidang banjir maksimum berada di kedalaman 640, 736,5, dan 825 cmbsf, sedangkan bidang transgresif berada di kedalaman 701, 765, dan 890 cmbsf.

\section{UCAPAN TERIMA KASIH}

Penulis mengucapkan terima kasih kepada Dr. Yusuf Surachman Djajadihardja yang telah memberikan izin atas penggunaan conto sedimen inti yang digunakan dalam penelitian ini. Terima kasih juga disampaikan kepada Dr. Luli Gustiantini dan Yuli Yulianah dari Pusat Penelitian Geologi Kelautan atas bantuannya dalam pencuplikan contoh sedimen.

\section{DAFTAR PUSTAKA}

Ardi, R.D.W., Maryunani, K.A., Yulianto, E., Putra, P.S., Nugroho, S.H. (2019). Biostratigrafi dan analisis perubahan kedalaman termoklin di Lepas Pantai Barat Daya Sumba sejak Pleistosen akhir berdasarkan kumpulan foaminifera planktonik. Bulletin of Geology, 3(2), 355-362. https://doi.org/10.5614/bull.geol.2019.3.2.3

Barron, J. A., dan KELLER, G. (1983). Paleotemperature oscillations in the Middle and Late Miocene of the northeastern Pacific: Micropaleontology, 29. 150-181.

Boltovskoy, E. dan Wright, R. (1976). Recent Foraminifera. Dr. W. June, B. V. Publisher, The Haque, Netherland. 515 hal.

Catuneanu, O., Galloway, W. E., Kendall, C. G. S. C., Miall, A. D., Posamentier, H. W., Strasser, A., \& Tucker, M. E. (2011). Sequence Stratigraphy: Methodology and Nomenclature. Newsletters on Stratigraphy, 44(3), 173-245. doi:10.1127/00780421/2011/0011

Dennison, J. M. dan Hay, W. W. (1967). Estimating the Needed Sampling Area for Subaquatic Ecologic Studies, Journal of Paleontology, 41(3), 706-708

Grimsdale, T.F., dan Van Morkhoven F.P.C.M. (1955). The ratio between Pelagic and Benthonic Foraminifera as a means of estimating depth of deposition of sedimentary rocks. In Proceedings 4th World Petroleum Congress Rome, Italy, Hlm. 473-491.

Gupta, B.K.S. (1999). Introduction to modern foraminifera. Dalam B.K.S. Gupta (editor). Modern Foraminifera. Kluwer Academic Publisher, Great Britain. Hlm.103-122.

Lagoe, M. B. (1987). The Stratigraphic Record of Sea-Level and Climatic Fluctuations in an Active-Margin Basin: The Stevens Sandstone, Coles Levee Area, California. PALAIOS, 2(1), 48. doi: $10.2307 / 3514572$

Lückge, A., Mohtadi, M., Rühlemann, C., Scheeder, G., Vink, A., Reinhardt, L., \& Wiedicke, M. (2009a). Monsoon versus ocean circulation controls on paleoenvironmental conditions off southern Sumatra during the past 300,000 years. Paleoceanography, 24(1). doi:10.1029/2008pa001627

Lückge, A., Mohtadi, M., Rühlemann, C., Scheeder, G., Vink, A., Reinhardt, L., \& Wiedicke, M. (2009b). Stable oxygen record, sea surface temperatures (Uk37) and 
total organic carbon content oof sediment core SO139-74KL. PANGAEA, https://doi.org/10.1594/PANGAEA.882099

Mitchum RM, Sangree JB, Vail PR et al. (1993) Recognising sequences and systems tracts from well logs, seismic data and biostratigraphy: examples from Late Cenozoic of the Gulf of Mexico. AAPG Mem, 35, 163-197

Murray. J. W. (2006). Ecology and Applications of Benthic Foraminifera. Cambridge Univ. Press. 426 hal.

Maryunani, K. A. (1998). Pola sebaran foraminifera dalam hubungannya dengan stratigrafi sikuen (Studi kasus: Daerah Blora dan sekitarnya/daerah lintang rendah). Proceeding ITB Vol. 30, No. 3. Hlm. 1-16

Schlager, W. (2010). Ordered hierarchy versus scale invariance in sequence stratigraphy. Int $J$ Earth Sci (Geol Rundsch), 99, 139-151. https://doi.org/10.1007/s00531-009-0491-8

Vail, P.R., Wormard, W.W. (1991). An integrated approach to exploration and development in the 90's: well $\log$-seismic sequence stratigraphic analysis. Gulf Coast Assoc Geol Soc Trans, 41, 430-650

Van Marle, L.J. (1989). Benthic Foraminifera from Banda Arc Region, Indonesia, and Their Paleobathymetric Significance for Geologic Interpretations of The Late Cenozoic Sedimentary Record. Free University Press, Amsterdam; 271 hal.

Wiedicke-Hombach, M., Ardhyastuti, S., Bruns, A., Delisle, G., Georgens, R., Hermawan, T., Kanamatsu, T., Lückge, A., Mothadi, M., Mühr, P., Rahadyan, T., Riyadi, A. S., Rühlemann, C., Schippers, A., Schlömer, S., Taufik, M., Teichert, B., Vink, A., Weiss, W., Wijaya, P. H., Wöhrl, C., Zeibig, M., dan Zoch, D. (2006). SUMATRA - The hydrocarbon system of the Sumatra Forearc, cruise report BGR cruise SO189 leg 2, Bundesanstalt für Geowissenschaften und Rohstoffe;, Hannover. https://doi.org/10.2312/cr_so189_2 